\title{
THE EVOLUTION OF MATING STRATEGIES IN BULLFROGS, RANA CATESBEIANA
}

\author{
RICHARD D. HOWARD ${ }^{1}$ \\ Division of Biological Sciences and Museum of Zoology, University of Michigan, \\ Ann Arbor, Michigan 48109
}

Received July 27, 1977. Revised February 23, 1978

Mating system theory is undergoing considerable revision and elaboration (for example: Fisher, 1958; Brown, 1964; Williams, 1966, 1975; Orians, 1969; Cody, 1971; Trivers, 1972; Alexander, 1975; Emlen and Oring, 1977; Alexander and Borgia, 1978). These theories are based upon Darwin's (1871) concept of how natural selection acts within and between the sexes: intrasexual selection, sexual competition between members of the same sex for mates, and intersexual selection, in which one sex is the selective agent for the other. Unfortunately, adequate data to test these theories are lacking for most organisms (but see Bateman, 1948; Savage, 1961; LeBoeuf, 1974; Chagnon, 1974; Jenni, 1974). In this paper, I present necessary data on how mating success varies within and between the sexes to test existing theories of sexual selection for one species, the bullfrog, Rana catesbeiana, and I extend current theoretical considerations to include how age should influence alternative male mating strategies.

Anurans are excellent animals to test theoretical predictions of sexual selection: since males fertilize eggs externally, there is no doubt about male parentage and, thus, relative male mating success. Such high confidence of paternity is lacking for most species with internal fertilization. Additional attributes of bullfrogs which make a study technically possible include (a) a tendency for chorusing males to form relatively dense aggregations thus facili-

\footnotetext{
${ }^{1}$ Current address: Department of Biological Sciences, Bowling Green State University, Bowling Green, Ohio 43403.
}

tating simultaneous observations on a large number of individuals, (b) a prolonged breeding season that provides ample time for repeated observations on all individuals, (c) individuals easy to capture and mark for individual field recognition (see also Emlen, 1968b), and (d) large body size providing good visibility at great distances. General life history information exists for bullfrogs (Wright and Wright, 1949; Noble, 1954; Conant, 1975); additionally, studies on demography (Collins, 1975) and mating behavior (Emlen, 1968a; 1976; Wiewandt, 1969) are available for the population under investigation here.

Bateman (1948), Williams (1966; 1975), and Trivers (1972) suggest that the greater material investment in offspring by females of most species should result in females maximizing their reproductive success by being more discriminatory than males with respect to mate quality. In contrast, males are predicted to maximize their reproductive success more often by maximizing the number rather than the quality of females fertilized. Such a dichotomy between the sexes in the basis for mate choice should really be viewed as a continuum; the magnitude of the differences between the sexes should be proportional to the relative total reproductive success possible if members of each sex attempted to produce additional offspring with other mates (see Dawkins and Carlisle, 1975; Boucher, 1977). The ultimate cause for these differences between males and females may result from a differential confidence of parentage (Alexander and Borgia, 1978): a female cannot be deceived that the eggs coming from her body are genetically related to her; however, a 
male can seldom be as sure that the young produced by his mate were sired by him. Thus, females are expected to invest much more initially in their offspring than males and to be more discriminating with respect to mate quality.

In monogamous (and polyandrous) mating systems male confidence of paternity should approach that of females. This should also be the case with an externally fertilizing species (Trivers, 1972) regardless of mating system. Since bullfrogs give no parental care after egg deposition, the relative investment pattern of the sexes in gametes should be the primary influence upon how each sex maximizes its reproductive success. An important consideration is how serial clutches devalue each other. Future matings by males should have little effect on previous matings and vice versa. The situation would probably differ for females, however. Females can maximize the number of matings by altering either the number of young per mating and/or the size of young produced. By depositing portions of her entire clutch with different males during a breeding season, a female may gain little more (or even less) reproductively than by depositing all her eggs with her first mate, and may also face an increased probability of predation during multiple matings. Alterations of egg size may seriously affect an offspring's chances for survival by jeopardizing its ability to compete with conspecifics or to avoid predators. Observations of female bullfrogs that mate twice in the same year indicate that both clutch size and egg size are affected (Howard, 1977; 1978).

Male-male competition should be greatest in those species in which males maximize number of mates. Such competition may lead to high variation in male reproductive success depending upon patterns of female choice (Orians, 1969). Selective regimes favoring maximizing number of matings in males and maximizing quality of matings in females may also produce sexual dimorphisms in morphology and behavior. The degree of sexual dimorphism in closely related species should be directly related to the intensity of malemale competition (Alexander et al., 1978). The type of male-male competition may vary in different species: for example, males may be territorial if (a) resources required by females are defendable (after Brown, 1964) (e.g., see Cronin and Sherman, 1977; Wells, 1977a), or if (b) females are clumped, males could defend them as resources as in elephant seals (LeBoeuf, 1974), or (c) even if no obvious resource occurs as in bird leks (Hogan-Warburg, 1966; Van Rhijn, 1973; Wiley, 1974).

Additionally, within a sex, individuals may employ different mating strategies to increase their reproductive success. The proclivity for alternative mating strategies should also be proportional to the amount of intrasexual competition for mates, and should therefore occur more often in males than in females. A mating strategy is defined here as a set of evolved characters (both morphological and behavioral) that function in obtaining sexual partners; the mating system for any species is usually characterized by the most frequently occurring mating strategy in the population; this includes number of mates per individual, how these mates were obtained, and degree of parental care.

A major influence on alternative male mating strategies in iteroparous species should be a male's age relative to competing males. Males, of different ages may vary markedly in size' and/or experience; these characteristics should not only influence male-male interactions but also patterns of female choice. Females are predicted to prefer older males not only because they may control resources of higher quality but also because they possess phenotypes that have demonstrated their ability to survive numerous environmental conditions. To the extent that heritable variations influence such survival ability, females may be choosing males on the basis of relative genetic quality. I suggest that a significant proportion of the variation in male reproductive success in iteroparous species will be explained by variations in age of males. Younger males 
then face two major disadvantages: stiff competition from older males for resources important to females or for females directly, and discrimination from receptive females on the basis of age. Younger males should avoid physical interactions with older males and deceive or coerce females to mate.

Three male mating strategies observed in bullfrogs will be discussed below: territoriality, male parasitism, and opportunism. Although any male, regardless of age, is physically capable of performing all three strategies, the predominant strategy used by a male is largely influenced by a male's age relative to competing males.

\section{Materials AND Methods}

\section{Study Area}

This study was conducted in 1975 and 1976 at Crane Pond in the Edwin S. George Reserve of the University of Michigan, located $39 \mathrm{~km}$ northwest of Ann Arbor, Michigan. The general habitat of the Reserve has been described elsewhere (Rogers, 1942; Cantrall, 1943; Cooper, 1958). Crane Pond has an area of approximately 2.14 hectares and consists of three distinct lobes. Each lobe varies in general habitat: (1) The west lobe consists of a dense central mat of water lilies, Nymphaea tuberosa, surrounded by a channel 2-3 m in depth. Dogwood, Cornus spp., and willow shrubs, Salix spp., border most of the shoreline. The west lobe is the deepest and consistently the coldest lobe in the pond. (2) The central lobe possesses a dense central mat of crowfoot (Ranunculus longirostris), pondweed (Potamogeton berchtoldii), Chara, and an unidentified species of sedge. Water depth in the central lobe varies from approximately 1 $m$ in the central regions to approximately $2 \mathrm{~m}$ in the peripheral channel. The shoreline is mostly open except for four willow trees, Salix babylonica, one at each corner, and a small group of aspen trees, Populus tremuloides, along the north central shore. This lobe contains regions of extremely warm water due to its shallowness and dense vegetation mat. (3) The east lobe consists predominantly of pondweed. The shoreline is almost completely surrounded by a dense oak-hickory forest with some willows, Salix spp., along the north and northeast shoreline. Water depth is approximately $1 \mathrm{~m}$; the east lobe generally is intermediate in water temperature but contains regions that may have the warmest water temperatures in the pond.

Crane Pond is bordered on its west and east shorelines by marshy areas that not only serve as overwintering sites for a large portion of the bullfrog population, but also may contain active choruses during the breeding season. Water flow is continuous between these areas throughout most of the year. Migration between choruses during the breeding season is almost exclusively limited to females; male bullfrogs tend to remain in one habitat for all breeding periods during $1 \mathrm{yr}$. Data on such sex-specific migratory behavior are possible because Crane Pond is completely enclosed by a $1 \mathrm{~m}$ high hardware cloth fence. Intensive monitoring of breeding activity in Crane Pond, however, precludes observations in other breeding aggregations due to temporal synchrony between nearby choruses.

\section{Animals and Methods}

Individuals collected either along the fence or inside the pond were sexed, measured, weighed, and marked for later identification. Three separate marking techniques were used in 1976: toe-clips, tattoos, and waistbands.

Unique combinations of toes were clipped past the distal phalanx to provide a means of permanent identification. Such toe-clips were recognizable between years although some regeneration of tissue was noted. The general toe-clipping scheme of George (1940) was followed except that thumbs were never removed; nor were more than two digits used on the same foot. I also did not clip adjacent toes on the same foot. 
As an additional marking scheme, I tattooed a unique number on each individual's abdomen with a battery powered Anacare tattoo machine. Tattoos faded, however, due to the continual sloughing off of ectodermal tissue; thus, their usefulness for identification between years is more limited. Within years, however, tattoos were valuable because they were often the only means of individual identification for individuals partially eaten by predators.

Loose-fitting waistbands provided a method of individual identification in the field. The method used here is similar to that of Emlen (1968b), except that I used surveyor's flagging tape to construct bands. A unique number was placed on each band with a permanent marker. I formed the tape into a band by gluing two ends together with cyanoacrylic glue. This method permitted rapid marking of individuals with waistbands proportional to their size. Loose-fitting waistbands were desirable to avoid abrasions. Individuals could be recognized at distances greater than $10 \mathrm{~m}$ without the use of binoculars.

Individuals were weighed in the lab with a Mettler P2000 scale and in the field with a 1,000 g Pesola scale. Preliminary tests indicated that the Pesola scale was within $5 \mathrm{~g}$ of the value given by the Mettler balance. Length measurements were obtained using a metric ruler mounted on a board with a nail at the origin to delimit the ischial bone. Successive measurements on the same individuals indicated an accuracy to within $2 \mathrm{~mm}$ in estimating length using this technique.

In 1976, a grid system was installed in Crane Pond using styrofoam buoys tied to weights. One buoy was placed every 7.62 m $(25 \mathrm{ft})$. The grid system permitted accurate mapping of individuals, thus providing detailed information on territory size, amount of movement, and areas of activity for each individual. Positions of individuals were transferred to specially prepared maps. At least two maps were made during daylight hours and at least four maps were made at night. I estimated amount of movement by measuring distances between successive sitings. Data obtained with this method should estimate minimum distance traveled because I assumed that individuals travel in straight lines to new sites. Such estimates are also assumed to be unbiased with respect to male size or mating strategy.

Mating behavior in this chiefly nocturnal species was observed using binoculars and a battery-powered head lamp. Observations were made from a boat and from $7 \mathrm{~m}$ observation towers constructed from scaffold material that I placed inside the pond near areas of activity. Artificial light usually had no detectable effect on most behaviors (e.g., calling, male-male interactions) but did disturb amplexed pairs. To avoid such disturbances, I identified males and locations of pairs from a distance of at least $15 \mathrm{~m}$ and did not approach them until egg deposition. During egg deposition, the pair could be approached without disturbance; I then identified females and again noted locations of egg masses.

Photographing various mating activities also had no apparent effect on behavior. Photographs of male-male encounters, amplexed pairs depositing eggs, and newly deposited egg masses were obtained in this fashion. Photographs of egg masses within 5-10 min of deposition provided a record from which clutch size could be estimated. During this time, eggs were essentially distributed homogeneously in a mono-layer on the water's surface. After $20 \mathrm{~min}$, an egg mass would begin to settle on submerged vegetation, and this technique would no longer be possible. Slides of egg masses were later projected on a grid and clutch size estimated by (a) obtaining the average number of eggs in 20 randomly chosen squares that were completely full of eggs, (b) multiplying the total number of completely full squares by this average, and then (c) adding to this figure the number of eggs counted in all partially full squares.

Estimates of embryo mortality were obtained by sequentially sampling individual 


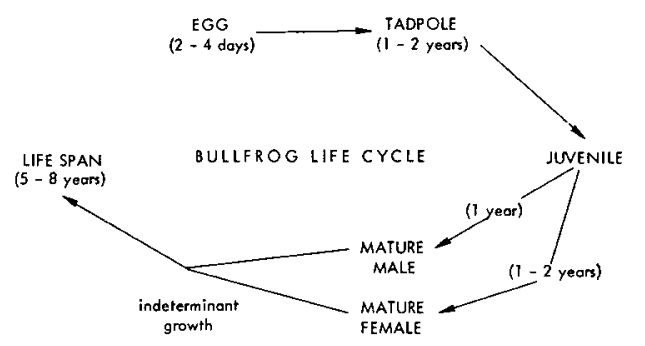

FIG. 1. General life cycle for bullfrogs in Crane Pond based on information collected by Collins (1975) and this study.

egg masses (usually every 10-12 h) until all eggs hatched. Mortality estimates were based upon 15,299 embryos from 164 samples collected from 27 egg masses. Average sample size was 93.3 individuals; $\mathrm{SD}=58.92$. All embryos were preserved in a weak (less than 6\%) formaldehyde solution for subsequent examination.

Two major sources of embryo mortality were recognized: developmental abnormalities and predation. I estimated percent predation and percent abnormality for each egg mass by using the maximum estimates for each from the latest developmental stage prior to stage 18 (after Gosner, 1960) that had a sample size of at least 50 individuals. I judged an egg as abnormal using Rugh's (1962) classification of abnormalities. Leeches, Macrobdella decora, were the major predators of embryos; leeches would envelop an egg and suck out the embryo. Predation was considered to occur when an egg was visibly punctured and the contents removed; remnants of egg capsules alone were not considered-sufficient evidence for predation because of the possibility of duplicating the same predation event.

Air temperature data were obtained from a hydrothermograph placed in a weather station near the shoreline of the west lobe.

Estimation of male chorusing activity levels was qualitative in nature; quantification was not possible due to variations in spatial distribution of males and variations in calling synchrony. Sustained choruses by a majority of males in the pond were designated as "good." Sustained choruses by only a few males were classified as "fair," and sporadic calling by any proportion of males in the population as "sporadic."

Male mating success was determined by direct observation of copulations. Using this criterion, I knew male parentage for $74 \%$ of known egg masses deposited in 1975 and $96 \%$ of known egg masses deposited in 1976 . The discrepancy between years resulted from matings during a violent electrical storm that precluded observations during one night of the mating season in 1975. I assume that both sets of samples were random samples of all copulations with respect to male size and/or age. Although male parentage could have been estimated based upon position of egg masses and positions of males preceding the storm, I chose not to do so to eliminate any possibility of error.

Only interactions between calling males were used in analysis of male-male encounters. This criterion excludes interactions between territorial males and parasitic males. It was not always possible to identify both males in an encounter because many encounters co-occurred in time or were widely separated in space. As a result, more encounters were observed than were used in the analysis of size related success in male-male aggressive encounters.

The descriptive analysis of alternative male mating strategies (Table 4) considers the possibility that individual males may employ all three strategies during one breeding season. Each of the 37 males in the analysis was classified into one of the three mating strategies depending upon his specific behavior patterns for each night considered. The analysis is limited to only those nights in 1975 in which "good" chorusing activity was observed $(N=13)$.

Various parametric and non-parametric statistical tests were used to analyze data: (a) $t$-tests $(t), F$-tests $(F)$, Pearson product moment correlation $(r)$, (see Sokal and 

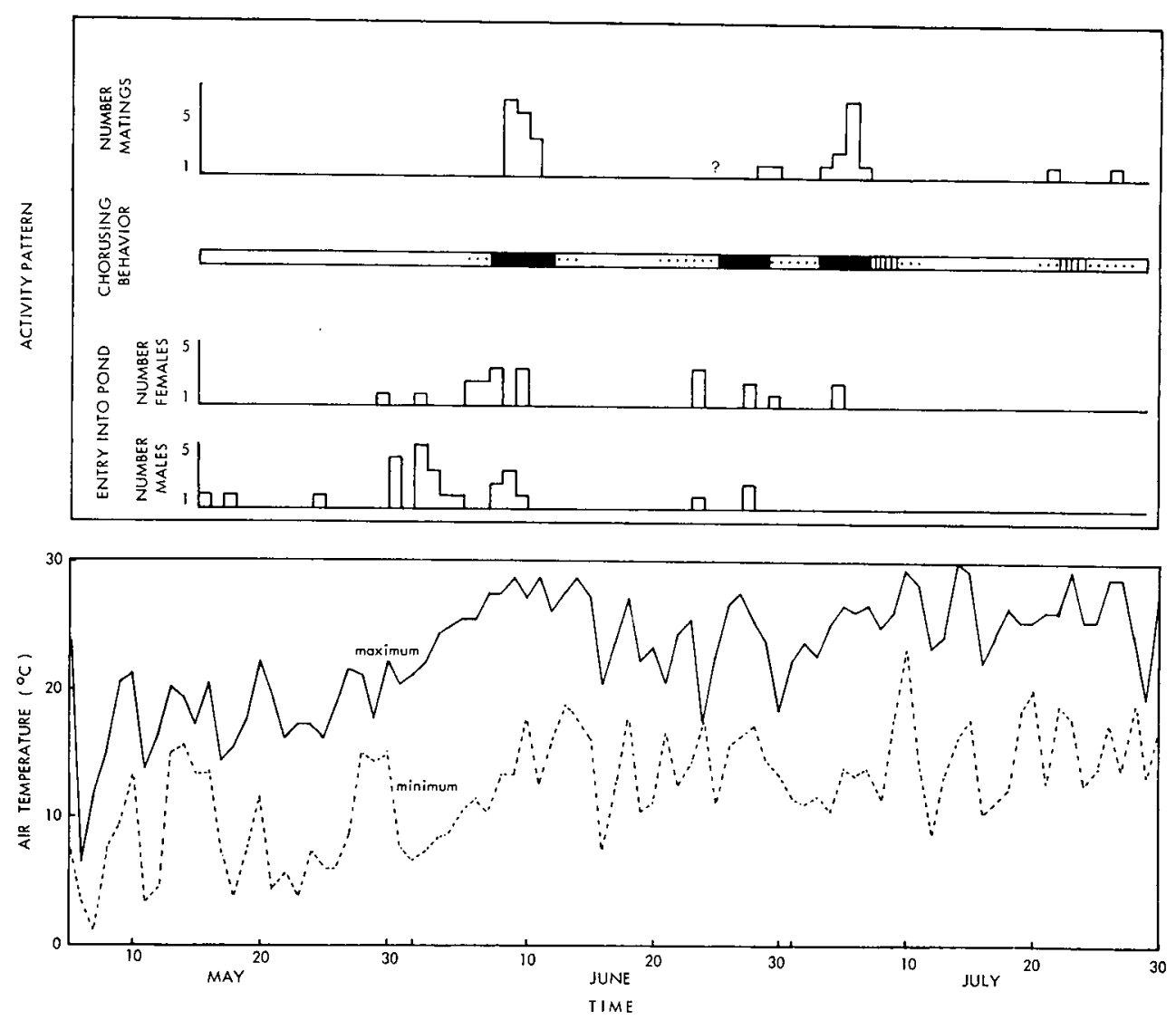

FIG. 2. Air temperature and activity patterns in bullfrogs in 1976. Bottom graph: maximum daily and minimum nightly air temperatures during the breeding season. Top graph: activity patterns, lower histograms indicate dates of entry into Crane Pond for males and females; males in late June, all 1-yr males; females, all age classes. Bar graph: male chorusing behavior, dots = "sporadic" calling, single lines = "fair" choruses, solid areas = "good" choruses. Uppermost graph: frequency of matings; question mark = possible but unobserved mating.

Rohlf, 1969; Wonnacott and Wonnacott, 1972); simple linear regression $\left(R^{2}\right)$ (see Draper and Smith, 1966); and analysis of covariance $(A N C O V A)$ (see Steel and Torrie, 1960); (b) Wilcoxon-Mann-Whitney $U$ test $(U)$, Chi square test $\left(\chi^{2}\right)$, and Spearman rank correlation $\left(r_{s}\right)$ (see Siegel, 1956; Wonnacott and Wonnacott, 1972).

\section{RESULTS}

\section{Natural History}

The life cycle for bullfrogs in Crane Pond is summarized in Figure 1 (see also Collins, 1975).
General variations in air temperature may affect activity patterns of bullfrogs (see Fig. 2). As temperature increases in late spring, frogs that overwintered in nearby marshes migrate into Crane Pond. Males generally precede females into the pond (for example, in 1976: $U=57.00$; $P=.0046 ; N=35$ ). Larger males often precede smaller males into the pond (in 1976: $r_{s}=-.44 ; P=.0406 ; d f=22$ ); this relationship may result in only a slight disadvantage to smaller males because most males are in the pond before acquisition of territories begins. For both years of my study, no males, regardless of size, 
entered the first chorus after mating activity had commenced.

Mating behavior occurs in June and July in most northern sections of the United States (Conant, 1975). However, in Crane Pond, mating activity is not continuously distributed throughout this time but occurs in two or three distinct periods (Fig. 2). I consider each period distinct because the individuals involved are separated both temporally and spatially. Only females that are at least 2 yr past metamorphosis mate during the early breeding period. I have also observed several older females mating a second time during later breeding periods. Occurrence of such multiple clutches in temperate zone anurans was first observed by Wells (1976) in green frogs, Rana clamitans. In the later breeding periods, 1-yr-old females may deposit their initial clutches. Similarly, 1-yr-old males may join later choruses often significantly changing the male size distribution between choruses (see below).

The general pattern of mating activities not only reflects the influence of temperature but also suggests past selection for synchronous breeding in females. Support for the latter hypothesis includes (1) abrupt termination of male chorusing behavior within one or two days after the mating of the last receptive female and (2) absence of male chorusing behavior during the subsequent 10 to 14 days.

Location of a chorus varies during the summer (Fig. 3) (see also Emlen, 1976). Most such movements coincide with the different breeding periods in $1 \mathrm{yr}$ and may be influenced by a deterioration in the thermal and/or vegetational quality of previous chorus sites. In 1976, successive choruses were found in regions of progressively cooler water temperature: the initial chorus occurred in the warmest region in the pond, succeeding choruses were in cooler regions, and the last chorus took place in the coolest area available. Water temperature differed in the various chorus sites which suggests that chorus movements are not influenced by prefer- ence for a specific thermal regime. However, relocations may function, in part, to avoid extreme water temperatures in previously warm areas during the potentially warmer midsummer days (Howard, 1978). Additionally, when a chorus reforms, vegetation in the previous site may differ markedly due to grazing by muskrats, Ondatra zibethica, and other herbivores, and due to senescence after flowering. Abrupt chorus movements also occur, for example in the first chorus, which suggests that other factors may influence some relocations. Some evidence indicates that such relocations may be due to the leech, Macrobdella decora, which is not only a significant predator on embryos but also parasitizes adults (Howard, 1978).

Relocations of choruses during a breeding season do not occur in all bullfrog populations. M. J. Ryan (pers. comm.) and J. Haas (pers. comm.) report that no such relocations occurred in the populations they studied.

In Crane Pond, choruses not only change position during the summer but also have niether a consistent spatial pattern nor a characteristic male density (see also Emlen, 1976). The three choruses in Figure 3 had a four-fold variation in male density. For this reason I use the term "chorus" only to mean a collection of acoustically interacting males; the term "chorus" denotes no spatial meaning. Observed spatial patterns of choruses seem to be influenced by water temperature and vegetational patterns. Males tend to defend territories at the edge of either shorelines or vegetation mats.

Emlen $(1968 a ; 1976)$ also investigated bullfrog mating behavior in Crane Pond. Although Emlen's study and this study coincide in many aspects of bullfrog mating behavior, our obsêrvations differ in several key regards, and our conclusions concerning the basic type of mating system differ substantially. Emlen concluded that the bullfrog mating system is similar to lek-breeding birds in which males defend positions in a well-defined arena that is unrelated to any resource. Emlen based 


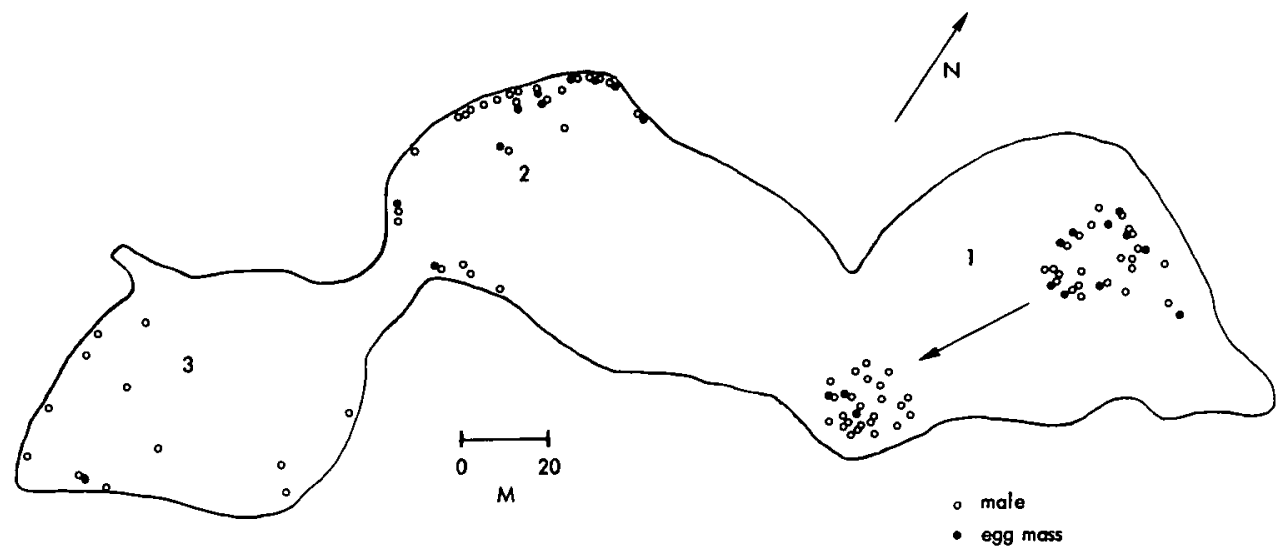

FIG. 3. Location of choruses in Crane Pond in 1976. Open circles = males; closed circles $=$ egg masses. Numbers $=$ temporal order of choruses: chorus 1, between 6 June-11 June; entire chorus shifted abruptly to new location (see arrow) on 9 June. Chorus 2, between 20 June-8 July. Chorus 3 , between 20 July-28 July.

this conclusion primarily on the observations that (a) larger males tend to occupy central positions in breeding aggregations, and (b) amplexed pairs left the chorusing site to deposit eggs. I could not determine any pattern of male size or age distribution in a chorus; indeed, it is usually not possible to identify the center of a chorus (e.g., choruses 2 and 3 in Fig. 3).

Choruses in which a central region could be identified (e.g., chorus 1, Fig. 3) provided no evidence for a relationship between male size and position. Chorus 1 occurred in two separate locations as a result of an abrupt movement of all males (see below). In the initial chorus, central males averaged $140.42 \mathrm{~mm}(\mathrm{SD}=7.45$; $N=12$ ) and peripheral males averaged $139.50 \mathrm{~mm}$ (SD $=11.61 ; N=12)$. The difference in male size between central and peripheral males was not significant $(t=0.23 ; P=.4101 ; d f=22)$. In the next chorus, central males averaged $136.50 \mathrm{~mm}(\mathrm{SD}=11.13 ; N=12)$ and peripheral males averaged $141.50 \mathrm{~mm}$ $(\mathrm{SD}=6.04 ; N=12$ ). Again, no significant difference occurred with respect to male size $(t=-1.37 ; P=.0923 ; d f=22)$.
Distributions of egg masses within these choruses also indicate that central positions (or central males) are not preferred by females (Fig. 3). Additionally, 70 of 73 (96\%) of the egg masses that I observed were deposited in the male's territory, thus supporting the hypothesis that males defend suitable oviposition sites.

The underlying reasons why choruses in the two studies differ in a center-edge pattern in the distribution of male sizes are unclear and worthy of future study. However, Emlen's observation that amplexed pairs leave choruses to deposit eggs could have been an artifact. I observed this behavior only if (a) the mated pairs were disturbed as a result of observations or (b) if the amplexed male was not a territorial male. Emlen and Oring (1977) suggest that as male density increases in polygynous species the mating system should shift from a resource defense polygyny to a non-resource defense polygyny (i.e., a lek system) because resources would become less defendable. Although this prediction remains a theoretical possibility in bullfrogs, I suggest that either (a) the required densities for such a shift have yet 


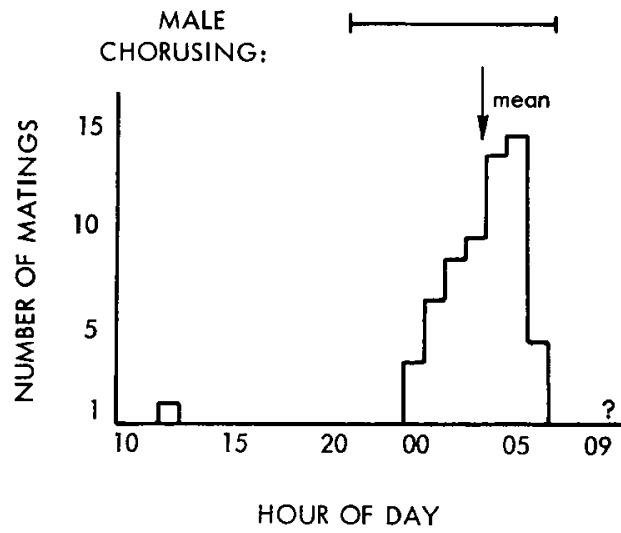

FIG. 4. Distribution of matings and male chorusing activity during the day (1975 and 1976).

to be observed, or (b) other conditions necessary for such a shift need to be specified. In particular, Emlen and Oring's prediction assumes that just because male ability to control resources may decline with density that female preference for suitable oviposition sites must also change. Thus I suggest that, even in extremely dense choruses, females should deposit their eggs near the site of amplexus (especially if finding a better oviposition site is costly or unpredictable). Present data support this hypothesis since even with a four-fold variation in male density, all egg masses are deposited within the male's territory.

The majority of mating activities occur at night; i.e., sustained choruses, most male-male encounters, and copulations (see also Emlen, 1976). However, ephemeral chorusing may occur during the day, particularly when choruses are first forming. Brief daytime chorusing could provide information to females and, perhaps incidentally to males, that may be more difficult to obtain at night. Such information includes variations in water temperature in different areas of the pond: temperature differentials between areas of the pond are maximal during the day due to variations in water depth, vegetation cover, and degree of water circulation.

Sustained choruses begin about 9:00 P.M. during the early breeding season and

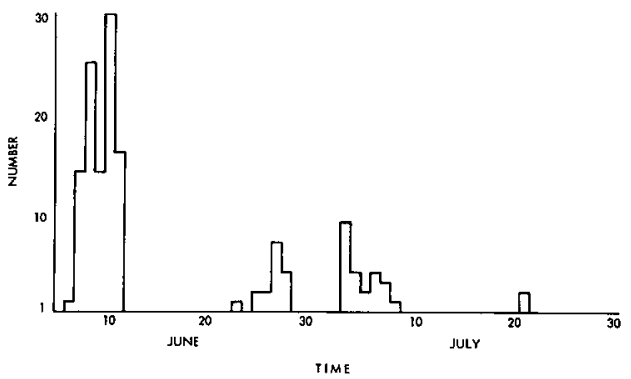

FIG. 5. Distribution of male-male aggressive encounter during 1976. Clusters correspond to three separate choruses. Initial chorus included 27 males, later choruses contained 32 males; male density was greatest in the initial chorus (see Fig. 3).

continue until dawn. Sustained choruses are not formed in later breeding seasons until at least midnight. Why such a difference occurs is unclear. Copulations occur during the early morning hours (Fig. 4) and in the latter choruses, copulations occur later in the morning $(\bar{x}=3: 88$ A.M.; $\mathrm{SD}=1.68 ; N=12$ ) than in the early chorus $(\bar{x}=2: 59$ A.M.; $\mathrm{SD}=1.38 ; N=15)$ $\left(t_{25}=2.20 ; P<.05\right)$.

The early chorus and later choruses differ in the frequency of male-male encounters (Fig. 5). The preponderance of malemale encounters in the first chorus is probably related to (a) the greater density of males in the early chorus, and (b) the average size of males in later choruses $(\bar{x}=$ $129.22 \mathrm{~mm}$; $\mathrm{SD}=13.80 ; N=32$ ) was significantly lower than that of the early chorus $(\tilde{x}=138.04 \mathrm{~mm} ; \mathrm{SD}=12.53 ; N$ =27) $\left(t_{57}=2.55 ; P<.02\right)$. This difference results from (a) the appearance of 12 first-year males in later choruses and (b) selective predation of larger males by snapping turtles, Chelydra serpentina. First-year males, comprising nearly $38 \%$ of the male population in later choruses, tended to avoid any encounters with larger males.

Copulation in bullfrogs is typically initiated when a female approaches a calling male and touches any part of the male with either her head or forelimb (see also Emlen, 1968a, 1976). The male then gives 


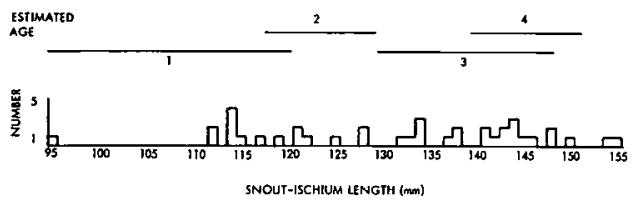

FIG. 6. Male size distribution in 1976. Bars above histogram indicate estimated age according to Collins (1975).

a sustained vocalization quite distinguishable from his usual territorial call (see Kolson, 1973) and clasps the female (amplexus). In bullfrogs, amplexus duration varies from 17 to $155 \mathrm{~min}(\bar{x}=49.31$; SD $=36.52 ; N=32$ ). Amplexus duration is significantly correlated with female size $(r=.405 ; P<.05 ; d f=29)$, perhaps resulting from additional time required for larger females to deposit a greater number of eggs. Additionally, two of the longest amplexus durations occurred when females were amplexed by small, non-territorial males; during these amplexes, females unsuccessfully attempted to dislodge the smaller males suggesting that these males were not considered suitable mates. However, no significant correlation existed between size of amplexed males and duration of amplexus. Such a relationship might occur in species in which females choose males after amplexus and/or male mating success depends on ability to remain amplexed when challenged by competing males. I never observed male bullfrogs contesting for amplexed females.

\section{Sexual Selection on Males}

Although in theory Darwin distinguished two forms of sexual selection, intrasexual selection and intersexual selection, it is difficult in practice to separate these phenomena, since males should be strongly selected to contest for only those criteria that females judge as important. In bullfrogs, the most important criterion influencing male reproductive success appears to be possession of suitable oviposition sites. Variations in size and/or experience of males should have a significant

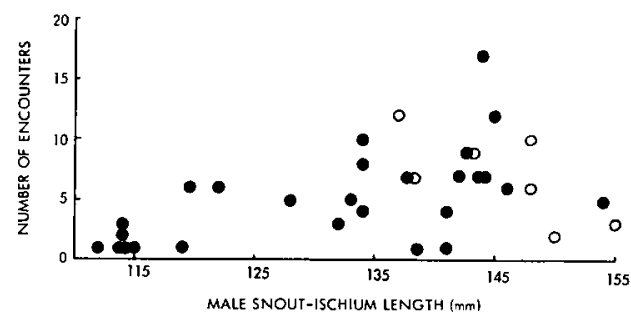

FIG. 7. Relationship between number of malemale aggressive encounters and male size in 1976. Closed circles $=$ males present through most of the season; open circles $=$ males that were preyed upon sometime during the season. $\left(r_{s}=.64 ; P<.01\right)$.

effect on the differential abilities of males to control resources of varying quality.

Figure 6 shows the size distribution of males in 1976. Bars above the histogram indicate male age (years past metamorphosis) as calculated by Collins (1975). Males competing for females may vary in size by as much as $60 \mathrm{~mm}$ in length and $230 \mathrm{~g}$ in weight. Males of different ages may also vary in experience that could affect fighting ability. In a species with indeterminate growth such as bullfrogs, it is difficult to separate advantages based on size from those based on experience, especially when age classes may overlap several size classes (but see below).

Male mating success may not only depend upon choosing good oviposition sites but also upon the ability to defend such sites from contesting males. Larger males were involved in more male-male encounters during the breeding season (Fig. 7) and won 78 of 108 observed male-male encounters $(72 \%)$, whereas smaller males won only nine encounters $(8.3 \%)$. The remaining 21 encounters occurred between males of similar size. Male-male encounters can be classified into two general categories: physical fights or wrestling matches, and threats or displays. Malemale encounters commence when two calling males approach each other emitting sustained vocalizations. In a fight, the two males clasp each other with their forearms (see. Fig. 8) and wrestle. Wrestling matches are contests of brute strength in which victorious males physically over- 


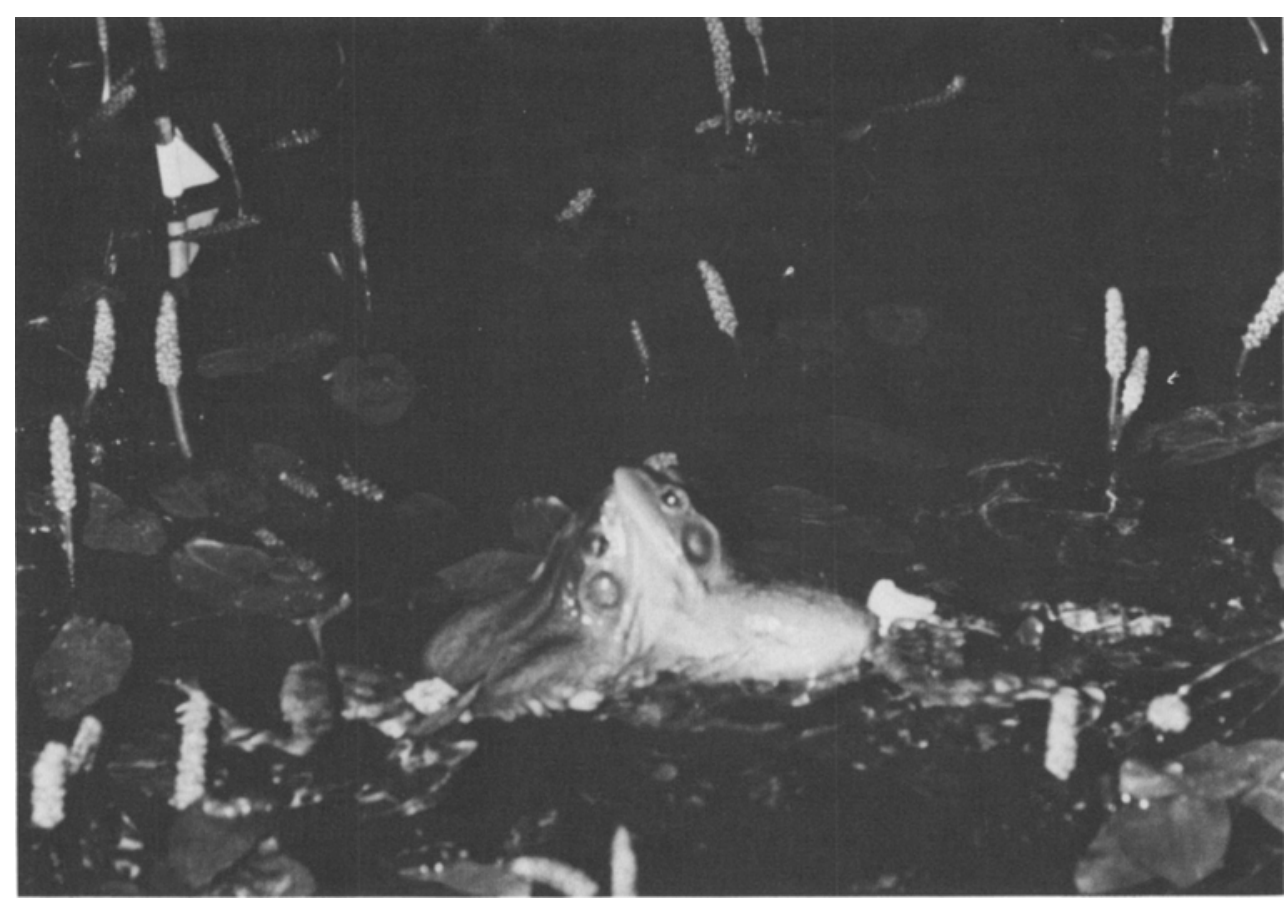

FIG. 8. Photograph of two fighting male bullfrogs. During fights males attempt to push their thumbs into their opponents' sides.

power their opponents, and may hold them under water for a few seconds to more than $10 \mathrm{~min}(\bar{x}=1.67 \mathrm{~min} ; \mathrm{SD}=$ $1.77 ; N=34$ ). Although most male-male interactions are brief, two males may interact in a series of wrestling matches for more than $1 \mathrm{~h}$. Threats or displays occur when one male retreats when challenged by another. Size differences between males in each type of encounter are examined in Table 1. Displays occur more often when interacting males differ greatly in size, suggesting that smaller males try to avoid any physical encounter with larger opponents. The rare chance for victory by smaller males is probably greatly outweighed by the certain loss of energy and risk of injury.

Male-male encounters between individuals of known age suggest that variations in male size may be more important in determining outcomes of encounters than are variations in past experience of males.
Older males won 32 of $33(97.0 \%)$ encounters with younger males. Within each age class, larger males still won 13 of 17 (76.5\%) male-male encounters. This analysis assumes that males of the same age class do not vary significantly in amount of fighting experience. Similar size advantages have also been described in other taxa (e.g., Sherman, 1976).

Advantages in male-male interactions must be converted into increased mating success to be favored by natural selection. Older, larger males not only physically dominate smaller males but also have increased mating success (Table 2). In bullfrogs, yearly variation in mating success of males exceeds that of females: the range of male mating success for $1 \mathrm{yr}$ is from 04 matings; females, however, may mate only once or twice per year, depending upon age. Variations between the sexes in lifetime reproductive success are currently under investigation and depend not only 
TABLE 1. Size differences between males in two types of male-male encounters.

\begin{tabular}{lcccc}
\hline \hline $\begin{array}{c}\text { Type of } \\
\text { encounter }\end{array}$ & $\begin{array}{c}\text { Mean size } \\
\text { difference } \\
\text { (mm) }\end{array}$ & SD & $N$ & $t$-value \\
\hline Fight & 7.34 & 5.988 & 65 & $2.14^{*}$ \\
Display & 10.20 & 7.678 & 41 & \\
\hline
\end{tabular}

$* P<.05$.

on potential variations in yearly mating success but also on differential survivorship by sex (Howard, 1979).

The relationship between male mating success and size and/or age is also demonstrable for individual males that were present in Crane Pond for both years of the study. As the result of 1 yr growth and/or experience, males tend to maintain or increase their mating success (Table 3 ). Thus, the same group of males that accounted for 8 of 46 known matings (17.4\%) in 1975, accounted for 13 of 26 known matings (50\%) in 1976.

Larger males not only obtain more matings than smaller males but also tend to be preferred by larger females (Fig. 9). Such a positive assortment by size provides an additional advantage for larger males: larger females deposit more eggs than smaller females $(r=.82 ; P \leqslant .05$; $d f=5$ ) (see also Collins, 1975). Since clutch size in bullfrogs may vary from 6,000 to more than 20,000 eggs (Collins, 1975; Howard, 1978), such size assortment could provide a significant advantage.

\section{Alternative Male Mating Strategies}

Alternative male mating strategies are predicted in those species in which variation in male reproductive success exceeds that of females and large differentials exist between males with respect to physical attributes and/or experience. In most iteroparous species, the majority of such differences between males are probably explainable by variations in age. Three such mating strategies occur in bullfrogs: territoriality, male parasitism, and opportunism.
TABLE 2. Correlation between male size and mating success.

\begin{tabular}{ccccc}
\hline Year & $\begin{array}{c}\text { Number } \\
\text { of males }\end{array}$ & $\boldsymbol{r}_{\boldsymbol{s}}$ & $\boldsymbol{P}$ & $\begin{array}{c}\text { Range } \\
\text { (females/ } \\
\text { male) }\end{array}$ \\
\hline 1975 & 58 & .259 & .0442 & $0-4$ \\
1976 & 37 & .590 & .0002 & $0-3$ \\
\hline
\end{tabular}

Territorial males call and actively defend areas from intruding males. By inflating their lungs, these males maintain a horizontal posture with most of their bodies above the water surface. An individual may defend a specific site for 3-14 days, depending upon his ability to repulse intruders and the length of time an active chorus persists in one area.

Parasitic males neither call nor defend areas in the pond; instead they remain close to territorial males, often less than $1 \mathrm{~m}$ away, and attempt to intercept females attracted by territorial males. The posture of parasitic males resembles that of females; their bodies are in a relatively vertical orientation with only the head above water. This posture is described by Emlen (1968a) as a "low" posture and probably decreases conspicuousness, thus reducing aggressive encounters. Territo-

TABLE 3. Influence of age on individual male mating success.

\begin{tabular}{cccc}
\hline \hline Male & $\begin{array}{c}\text { Number of } \\
\text { matings } \\
(1975)\end{array}$ & $\begin{array}{c}\text { Number of } \\
\text { matings } \\
(1976)\end{array}$ & $\Delta$ \\
\hline $5^{*}$ & 1 & 2 & + \\
9 & 1 & 1 & 0 \\
11 & 1 & 1 & 0 \\
$13^{*}$ & 1 & 1 & 0 \\
$15^{*}$ & 0 & 0 & 0 \\
21 & 1 & 1 & 0 \\
23 & 1 & 1 & 0 \\
29 & 0 & 2 & + \\
$31^{* *}$ & 1 & - & + \\
41 & 0 & 1 & + \\
$43^{*}$ & 1 & 2 & + \\
$47^{* * *}$ & 0 & 1 & $P=.031$ \\
& & & (Sign Test) \\
& & &
\end{tabular}

* Died in chorus.

** Died in amplexus.

*** Left chorus. 


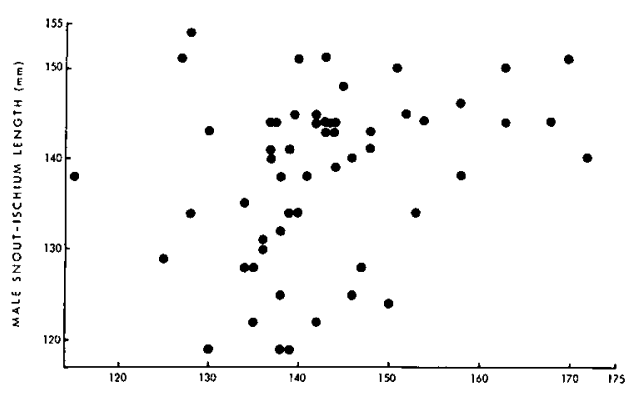

FEMALE SNOUT-ISCHIUM LENGTH Imm

Fig. 9. Relationship between male size and female size for 55 mated pairs observed in 1975 and $1976 ; r_{s}=.34, P=.0093$.

rial males, however, spend a considerable proportion of their time interacting with parasitic males. Most interactions involve aggressive attempts to disperse parasitic males; although sometimes territorial males attempt to amplex their parasites, suggesting that deception may also be involved. Territorial males rarely catch parasitic males because the characteristic aggressive vocalization and rather slow approach of the territorial male provide parasitic males with ample opportunity for retreat.

Similar parasitic strategies have been reported in other anurans (e.g., Wells, $1977 a$ ) as well as other taxa (e.g., Cronin and Sherman, 1977). Documentation of such alternative male mating strategies will doubtlessly occur for many species as a result of intensive field studies.

Opportunistic males call from specific areas and appear like territorial males; however, these males do not defend their calling sites. If challenged, opportunistic males flee to another area and resume calling. Such temporally territorial males are often found in various parts of the chorusing site during any one night.

Table 4 summarizes how males using the three alternative strategies can be separated on the basis of size, movement, and aggressive behavior. Territorial males are significantly larger than both parasitic males $(U=477.50 ; P<.0001)$ and opportunistic males $(t=3.04 ; P=.0026)$. Opportunistic males are also larger than parasitic males $(t=11.91 ; P<.0001)$. Thus, territorial males tend to be the largest, oldest males in the population, opportunistic males tend to be of intermediate size and age, and parasitic males are the smallest and youngest males in the population. Opportunism may be a transitional stage between parasitism and territoriality.

Opportunistic males move much more during choruses than territorial males $(U=$ 1133.0; $P<.0001)$ and parasitic males $(U$ $=470.0 ; P<.0001)$. In addition, the amount of movement of parasitic males significantly exceeds that of territorial males $(U=2637.5 ; P<.0003)$. These data reflect the relatively sedentary habits of territorial males and the relatively mobile habits of opportunistic males; parasitic males are intermediate in their movements because individual males may sometimes parasitize two territorial males in one night.

The pattern of male-male encounters also differs with respect to the strategy employed. Parasitic males are involved in fewer aggressive encounters than either territorial males $(U=3470.0 ; P=.0013)$ or opportunistic males $(U=808.0 ; P=$ .0225). Most encounters involving parasitic males occur when they are success-

TABLE 4. Description of male mating strategies on the basis of size, movement, and aggressive behavior.

\begin{tabular}{lcccccccc}
\hline \multicolumn{1}{c}{ Strategy } & $N$ & $\begin{array}{c}\text { Mean } \\
\text { size } \\
(\mathrm{mm})\end{array}$ & SD & $\begin{array}{c}\text { Mean } \\
\text { movement } \\
(\mathrm{m} / \mathrm{h})\end{array}$ & SD & $\begin{array}{c}\text { Mean } \\
\text { number } \\
\text { encounters } \\
\text { per night }\end{array}$ & \multicolumn{2}{c}{$\begin{array}{c}\text { SD } \\
\text { Percent } \\
\text { fights }\end{array}$} \\
\hline Territoriality & 208 & 139.90 & 8.260 & 2.61 & 3.584 & .510 & .994 & 74.3 \\
Parasitism & 76 & 112.83 & 10.706 & 4.02 & 3.066 & .087 & .285 & 20.0 \\
Opportunism & 43 & 135.67 & 8.524 & 7.08 & 4.616 & .511 & 1.032 & 28.6 \\
\hline
\end{tabular}




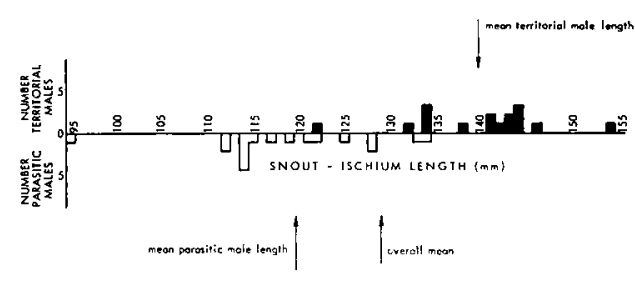

FIG. 10. Size distributions of territorial males and parasitic males in 1976 . Territorial males, above the horizontal axis in dark bars; parasitic males, below the axis in open bars.

fully captured by territorial males. Territorial and opportunistic males do not differ in number of male-male encounters $(t=0.01 ; \quad N . S$.$) ; however, territorial$ males are involved in nearly three times as many fights as opportunistic males (see Table 4). Thus, the tendency for opportunistic males to be involved in a greater proportion of displays suggests a strategy to avoid all physical encounters with nearby territorial males.

The extreme size difference between territorial males and parasitic males is illustrated in Figure 10. Observations indicate that the largest, oldest territorial males are selectively parasitized. In $\mathbf{1 9 7 5 ,}$ territorial males which were parasitized were significantly larger than unparasitized territorial males $(t=3.42 ; P \leqslant .01$; $d f=48$ ). In that year, parasitic males comprised a small proportion of the population: eight parasitic males were observed in a population of $58(13.8 \%)$. In contrast, parasitic males accounted for a much larger fraction of the population in 1976: 16 of 37 or $43.2 \%$ of the males displayed parasitic behavior. As a result, most territorial males, regardless of size, were parasitized at least once during the various breeding seasons. However, some degree of selectivity for larger territorial males still occurred (Fig. 11). More parasitic males were usually found near larger territorial males than smaller territorial males.

Males of different sizes employing predominantly different mating strategies vary in the probability of mating success (Fig. 12). Mating probabilities are ob-

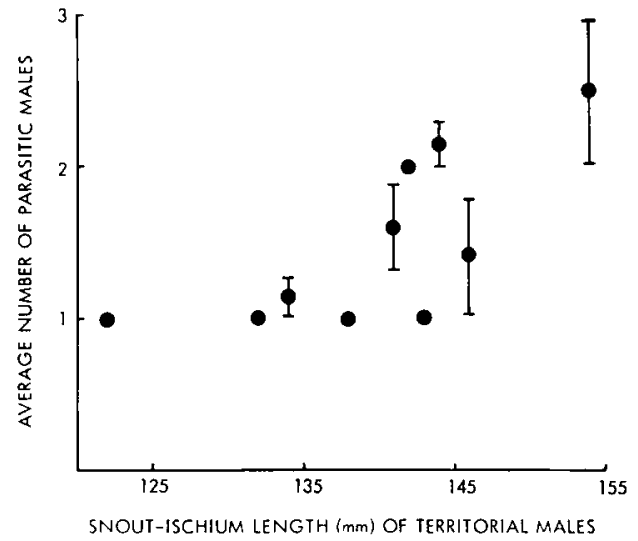

FIG. 11. Relationship between average number of parasitic males near territorial males and size of territorial males in 1976. Circles $=$ mean $\pm \mathrm{SE} ; r_{s}=$ $.42 ; P<.001$; correlation based on raw data, $n=$ 61.

tained by dividing the total number of males obtaining at least one successful copulation by total number of males in that size class. The size classes, however, cannot be divided into discrete classes by mating strategies since males of all size classes perform all types of strategies with the possible exception of large territorial males, which were never observed in parasitic roles. Figure 12 refers to the success of different strategies in only the most gen-

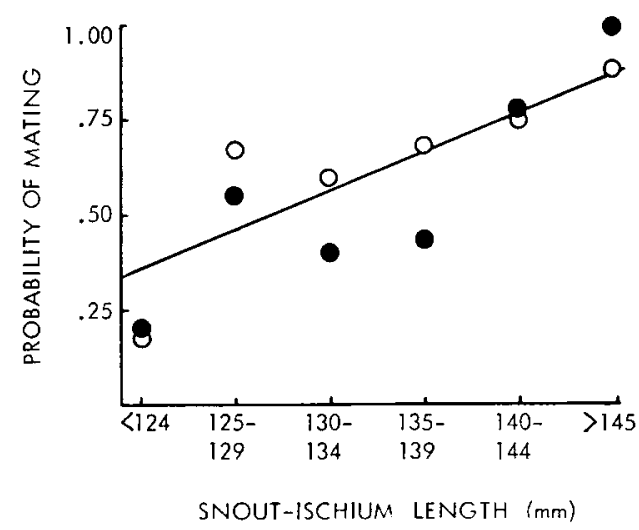

FIG. 12. Regression analysis of the probability of mating success in males vs. male size. Closed circles $=$ males in 1975; open circles $=$ males in 1976 . Regression equation is $Y=0.02 X-2.64 ; \mathrm{R}^{2}=$ $.72 ; P=.0005 ; \mathrm{SE}=0.14$. 


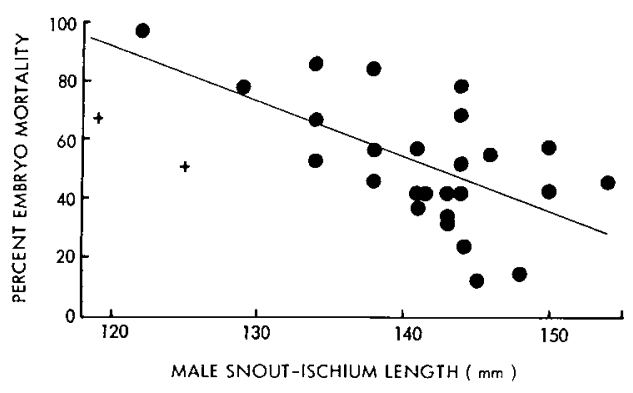

FIG. 13. Regression analysis of percent embryo mortality vs. male size in 1976. Crosses $=$ non-territorial males and were excluded from the analysis. $Y=-0.02 X+3.24 ; R^{2}=.37, P=.0012 ; \mathrm{SE}=$ .18 .

eral way: males predominantly employing a parasitic strategy are rarely successful: parasitic males obtained only two of the observed 73 matings; males employing predominantly a territorial strategy are highly successful; males usually employing an opportunistic strategy are intermediate in mating success. The regression equations for the 2 yr do not appear to differ $\left(F_{2,8}=.33 ; N . S.\right)(A N C O V A)$. The assumption of equal variances about the regression lines necessary for this analysis does not appear to be violated $\left(F_{4,4}=\right.$ $1.11 ; N . S$.$) . Such repeatability suggests$ that for the $2 \mathrm{yr}$ of my study male size was the major determinant of a male's mating success. This relationship was not significantly altered by the yearly variations observed in such factors as differences in the average size of males in $2 \mathrm{yr}$, total population number, and density of males in different choruses. This does not preclude the possibility, however, that variations in these parameters could greatly affect male mating success under other circumstances.

\section{Female Choice}

Bateman (1948) and Trivers (1972) hypothesize that increased parental investment by females should result in that sex being more discriminatory with respect to mate quality. As Orians (1969) suggests, female discrimination can result in a high variation in male reproductive success if males differ greatly in quality. Two major criteria for mate quality can be considered: resources that males possess as estimated by territorial quality and male phenotypic attributes that may indicate overall vigor, or to some extent a male's genetic quality. In some species, females may use both criteria for mate selection; in others, one criterion or the other may predominate. Whether or not males possess resources that are important to females may depend upon the defendability of resources (Brown, 1964). Factors influencing territoriality of this sort include the spatial distribution of resources, male density, and female breeding synchrony. Adequate support for the hypothesis that female choice is influenced by male resources includes the proof that females actually make use of a male's territory and that variations in the ability of males to control territories of high quality influence variations in male mating success. Adequate proof for the hypothesis that female choice is solely influenced by male genetic quality includes proof that genetic variations producing specific phenotypic characters solely influence variations in male mating success.

Female bullfrogs use a male's territory as an egg deposition site. Out of 73 observed copulations, only three instances occurred in which females did not deposit their eggs at the original site of amplexus. The exceptions include (1) a parasitic male that successfully amplexed a female but was driven from the site of amplexus by the territorial male and (2) two cases in which I disturbed the amplexed pairs by approaching too closely.

Variations in the ability of males to control high quality territories can influence male mating success. My estimates of territorial quality are based on variations in embryo mortality in different egg masses. Two sources of embryo mortality were considered: developmental abnormalities and predation; the major predators on embryos were leeches, $M$. decora, which are also significant predators on other anuran embryos (Brockelman, 1969; pers. obs.). 
I assume that variations in embryo mortality result from underlying environmental differences in oviposition sites that can be defended by individual males. Two major environmental variables that could affect embryos are considered: average water temperature and variations in physical structure of aquatic vegetation. Both factors can be directly related to embryo mortality (see Howard, 1978). The general hypothesis tested is that the ability of males to defend premium oviposition sites should be related to their size (age) such that larger (older) males should be better able to defend the best sites available. Figure 13 presents data in support of this hypothesis; larger, older males do indeed seem to be defending better oviposition sites as judged by embryo survival.

The ability of females to discriminate mate quality is usually considered a static phenomenon. However, just as it is possible for males to improve their ability to attract mates with increasing age, females may improve their ability to discriminate mate quality with increasing age. If such a phenomenon occurs, younger, less experienced females should be much more variable with respect to quality of chosen mates than older, more experienced females. Data presented in Figure 9 support this reasoning: if females are divided into two age groups, $\leqslant 3 \mathrm{yr}$ and $>3 \mathrm{yr}$ old, younger females are significantly more variable than older females with respect to quality of preferred mate (as estimated by male size) $\left(F_{43,10}=3.25 ; P<.0249\right)$. Advantages that larger females obtain by mating with larger males are also possible for younger, smaller females. I can find no evidence indicating a disadvantage for small females to mate with large males. Licht (1976) suggests that in Bufo americanus, size assortment results from maximal fertilization of eggs when mated pairs are similar in size. No such phenomenon was observed in bullfrogs. Additionally, there are no behavioral indications that (a) males ever reject any receptive female regardless of size or that (b) females compete for large males assuming that large females possess some size advantage. Thus, there is evidence that in bullfrogs, female as well as male mating behavior may be significantly influenced by age.

\section{DISCUSSION}

For any species, patterns of female choice can influence both the amount of variation in male reproductive success and the occurrence of alternative male mating strategies. Male attributes that females may consider important include (a) resources that provide proximate gains in terms of offspring survival and (b) genetic quality as estimated by phenotypic attributes that may provide ultimate gains by influencing mating success of surviving offspring. The influence of proximate gains on patterns of female choice can be demonstrated in bullfrogs (see above) as well as many other species (for example, Watson and Miller, 1971; Gentry, 1972; Howard, 1974; Wells, 1977a). No empirical evidence exists for any species that patterns of female choice are solely determined by variations in male genetic quality. However, both variations in male genetic quality and ability to control resources should be considered for a complete understanding of how female choice influences variations in male reproductive success.

In most iteroparous species, variation in age can significantly affect variation in female choice, male mating strategies, and male reproductive success. Data presented above support the hypothesis that female bullfrogs increase their ability to discriminate mate quality as they grow older. Age differences between males may influence their ability both to control resources and demonstrate genetic quality.

Fisher (1958) suggests that the evolution of a male trait by intersexual selection begins with females evolving a preference for male traits that indicate a high degree of ecological fitness. As intensity of female choice increases, the trait may develop to such an extent that it actually lowers ecological fitness; this reduction in survival ability is offset, however, by increased re- 
productive success of males possessing the trait. I assume here that such variations in male survival ability accurately reflect variations in male genetic quality.

When such intersexually selected traits begin to evolve, variations in genetic quality of males (as reflected by their phenotypes) should account for a substantial proportion of variation in male reproductive success, and variations in ages of males should account for very little of the variation in male reproductive success. However, as a sexually selected trait continues to evolve, underlying genetic variability for the trait will decrease, and variations in males with respect to size and/or experience will begin to account for more of the variation in male reproductive success. Females will continue to discriminate against males possessing lower genetic quality (as reflected by their phenotypes) but such discrimination eventually will resolve only minute variations in male genotypic quality. Male age could be the female's best indicator of a male's genetic quality. Older males can demonstrate that they possess genes that have survived the vagaries of numerous past environments. Such information is less complete for younger males. Older males are predicted to demonstrate clearly their age either in morphological attributes (e.g., body size or plumage development) and/or behavior (e.g., experience in mating behavior). Selection should also be very intense on younger males to obtain quickly an "old" phenotype. Young males are not expected to achieve a phenotype (e.g., body size) that will deceive females successfully for three reasons: (1) Physiological factors limit growth rate; (2) risks involved in maximal growth rates could jeopardize future reproduction; and (3) regardless how large a male can grow in 1 $\mathrm{yr}$, the same male can grow larger in $2 \mathrm{yr}$. As a result, selection for rapid attainment of an "old" phenotype in young males may only reset the optimal male phenotype to a new level, resulting in increased sexual dimorphism.

Williams (1975) suggests that the ad- vantage of sexual reproduction is to produce offspring with diverse genotypes so that some will survive and reproduce in unpredictable future environments. Older males at least demonstrate that they possess genes that have the ability to survive through a longer succession of past unpredictable environments than younger males can. Although there is no necessary correlation between survival of genes in past unpredictable environments and future unpredictable environments, genes that can survive a wider range of past unpredictable environments should generally have a higher probability of surviving in future unpredictable environments; even if this probability is low it may be the best characteristic available to females. Females that mate with older males should generally increase the probability that their offspring can survive unpredictable future environments compared to females that mate at random with respect to age of mate.

I predict that females discriminating solely on the basis of genetic quality should mate with very old males even if their choice results in mating with a slightly less genetically fit older male rather than a younger and more genetically fit male. The major portion of the younger male's reproductive fitness will not be realized until he is older. Females cannot see genotypes, only phenotypes, and there will still be a greater degree of uncertainity with respect to the genetic quality of a younger male. Senescence (see Williams, 1957; Hamilton, 1966) in very old males could complicate female choice of male genetic quality based upon phenotypes. Such a deterioration in a male's phenotype results from maximizing reproductive success at earlier ages. Some males may also live to very old age by limiting earlier reproductive activities. In general, mating success should increase with age, and the probability that highly successful males will survive to very old age should be low.

In contrast, if female choice is based on the quality of resources controlled by males, the increased size and experience 
of older males should enable them to acquire better territories than younger males, even assuming no genetic variation. Selection on younger males to show an "old" phenotype may be reduced because now younger males would encounter another cost: aggressive encounters with older males. Intense male-male competition probably accounts for delayed maturation in males of most highly polygynous species (Selander, 1965; 1972; Wiley, 1974; and references therein). Bullfrogs are not typical of this general pattern. Males tend to mature earlier than females (Fig. 1). Such a reversed sexual dimorphism may result from increased costs young females experience by breeding during their first year.

Senescence again presents a possible complication: very old males may no longer be able to secure and maintain good territories. Thus, females are predicted not to mate with very old males because of the effect of poor territorial quality on survival of young, even though very old males may possess genes that increase the probability of greater reproductive success of young if they do survive.

The relative importance of variations in male genotypic quality or ability to control resources on female choice probably varies between species. I suggest that in species in which both criteria are theoretically possible, female choice will be influenced more by resources a male possesses because of their immediate impact on offspring survival. Even if genetic quality has some influence on ecological fitness in bullfrogs, all adult males regardless of age have demonstrated their ability to survive extremely high juvenile mortality. Differentials in genetic quality between males of different ages may still be possible but must be rather slight after such intense selection. Additionally, variations in territorial quality present an immediate advantage for females (Fig. 13). However, separation of male genetic quality and male territorial quality may be impossible since both are predicted to covary with age.
Age dependent mating strategies are expected in many species due to the predicted female preference for older males and the greater ability of such males to control high quality resources due to imbalance in size and/or experience. Expression of age-dependent male mating strategies is expected to be more pronounced in highly polygynous species. Intense male-male competition in such species usually selects for increased size and/or fighting ability in males (see Alexander et al., 1978). Male competitive ability in such species should be an age-dependent process. For younger males, costs of physical encounters with older males usually outweigh benefits (probability of obtaining mates). Younger males not only lose more male-male encounters increasing risks of injury and mortality but also should have a lower chance of obtaining females. Both the opportunistic and parasitic strategies observed in young bullfrogs appear to function to decrease costs of territorial behavior.

Opportunistic bullfrogs actively seek out territories recently vacated due to movement or predation of territorial males. These young bullfrogs will occupy such territories until threatened by older males, thereby reducing the costs and risks of aggressive encounters. The probability of mating success for opportunistic males is relatively low (see above); however, one night I observed an opportunistic male successfully fertilize two females in a territory vacated by the predation of the original territorial male.

Male parasitism may best be explained using a model analogous to that proposed by Orians (1969) to describe the evolution of polygyny. As variation in quality of habitat patches increase, young males which can only obtain inferior breeding territories as a result of costly competition with older males may better increase their mating success by associating with older territorial males. Young males using such a parasitic strategy should be favored in a fashion analogous to the way selection is suggested to act on females. Association 
of young males with older males in some primate species (e.g., Krummer, 1968; Dunbar and Dunbar, 1975) suggests that young males may also capitalize on the ability of older males to maintain harems. For male-male parasitism to evolve, the probability that young males can successfully mate with females attracted by larger, older males may be similar to the probability that younger males can attract females by themselves; however, the energetic costs and risks of injury and predation involved in male-male parasitism are probably much lower relative to those encountered in territorial competition. Thus, relative benefits of competition for territories and male parasitism do not necessarily differ for young males; but costs of being a parasite are lower than costs experienced in territorial competition. Selective parasitism of very large males in bullfrogs (Figs. 10 and 11) provide additional support for such a threshold model.

Ecological conditions that may influence the occurrence of alternative male mating strategies include male density, age structure of males in the population, and temporal patterns of female receptivity.

In low male densities, costs of being territorial may be reduced and young males may become territorial. If in the same habitat male density is increased, costs of defending a resource should increase and young males should cease territorial behavior. In extremely high male densities, males of all ages may cease territorial behavior and mating success may be a function of a male's rank in a dominance hierarchy; in this situation, a male's age should directly influence his rank. Density-induced switches from territoriality to dominance hierarchies have been demonstrated in many animal taxa (e.g., fish, Fabricius and Gustafson, 1954; mammals, Davis, 1958; birds, Davis, 1959; reptiles, Brattstrom, 1974).

Age structure of males in a population should have a pronounced effect on male mating strategies. In the simplest case, when the age structure of the population consists of only one age group, all males should be expected to perform the mating strategy that maximizes reproductive success for the top age class: in the absence of old males, young males should use only those strategies usually observed in older males (e.g., become territorial). This phenomenon is often seen at the very end of a breeding season in many species when older males terminate reproductive behaviors, for example, bullfrogs (pers. obs.) and northern fur seals, Callorhinus ursinus (Bartholomew, 1959). Costs of territoriality for young males in this case should be weighed against the benefits of possible mating success and increased experience. An additional hypothesis based upon this reasoning is that as variance in male age is reduced in a population in which territorial males compete for females, more aggressive encounters should occur. Only in situations in which males are similar in age (size and/or experience) do the benefits (probability of winning) match the costs of fighting for both males. Such a phenomenon occurred in 1976: compared to later choruses, the initial chorus had less variation in male size and more male-male encounters. However, these choruses also differed significantly in male density (Fig. 3) which could also have produced these results.

Another factor influencing age-dependent male mating strategies is temporal availability of females. Extreme synchrony of female sexual receptivity should reduce variance in male reproductive success (Trivers, 1972) and male-male aggression because (1) high costs of aggressive behavior may not be compensated by an increase in mating success and (2) time spent in aggressive encounters means time lost for copulating. Wells (1977b) summarizes available literature on this topic for anuran amphibians: species that only breed for a short time period ("explosive breeders") are characterized by males actively searching for females; male aggression, if present, mainly involves contesting for amplexed females. Low variation in male reproductive success in most such 
species is predicted to preclude the evolution of alternative mating strategies.

In some species, high variation in reproductive success may result in alternative mating strategies that are unrelated to age. Such mating strategies may also result from (1) different genotypes with respect to mating strategies-for example, in red deer, Cervus elaphus (Darling, 1937); ruffs, Philomachus pugnax (HoganWarburg, 1966; Van Rhijn, 1973) and (2) developmental differences that persist throughout an individual's lifetime-for example, in some species of bees (Alcock, 1977) and dung flies, Scatophaga stercoraria (Borgia, 1978).

In conclusion, patterns of female preference that produce large variations in male reproductive success may also result in alternative male mating strategies. Males use alternative mating behaviors to reduce competition from preferred males and to bypass female choice.

\section{SUMMARY}

Variation in reproductive success within and between the sexes was investigated for $2 \mathrm{yr}$ in bullfrogs, Rana catesbeiana. Number of successful matings per male ranged from zero to four per year; number of successful matings per female ranged from one to two per year.

The polygynous mating system of bullfrogs appeared to result from the differential abilities of older, larger males to control oviposition sites preferred by females. Thus, older, larger males controlled territories of higher quality as judged by lower percent embryo mortality prior to hatching. Factors affecting embryo mortality included developmental abnormalities resulting from high water temperature, and predation of embryos chiefly by the leech, Macrobdella decora.

Females deposited their egg complement in the territory of their mate in 70 of 73 observed copulations. Male territories were used as oviposition sites at both low and high densities. No pattern was observed in the spatial positions of males in a chorus with respect to age, size, or mating success.

Younger males employed two alternative mating strategies: (1) male parasitism-associating with an old, large territorial male and intercepting any females attracted by the territorial male; (2) opportunism-becoming temporally territorial in a recently vacated territory until threatened by a nearby large territorial male. Both strategies appeared to reduce competition from older, larger males and to bypass female choice.

The ability of females to discriminate mate quality also appeared to be age dependent. Younger females were significantly more variable with respect to the quality of mate that they chose than were older females. Older females consistently selected the oldest, largest males in the population as mates.

Two aspects concerning the influence of male age on male reproductive success were discussed. (1) Male age should influence the outcome of male-male competition for territories or for females directly. (2) Female choice should include discrimination of males on the basis of male age not only because older males can control higher quality resources but also because older males display a phenotype that has successfully survived a wider range of environmental conditions than younger males. Such survival ability could provide information concerning the genetic quality of a male.

\section{ACKNOWLEDGMENTS}

I am deeply indebted to R. D. Alexander, G. W. Fowler, A. G. Kluge, and D. W. Tinkle for the advice, criticisms, and assistance they generously provided. I am especially grateful to R. D. Alexander for his advice, encouragement, and tremendous insights which were freely given during my entire graduate career. I appreciate the field assistance provided by Drs. Alexander and Tinkle. I also thank M. Flinn, M. F. Hirshfield, S. Moody, and $T$. Wurster for their assistance in the field. J. Haas, M. J. Ryan, P. 
W. Sherman, and K. D. Wells provided many helpful suggestions on an earlier manuscript.

This paper is part of a dissertation submitted to the University of Michigan in partial fulfillment of the requirements for a $\mathrm{Ph} . \mathrm{D}$. This work was supported by a National Science Foundation Doctoral Dissertation Grant under the guidance of R. D. Alexander, Theodore Roosevelt Memorial Fund Grant, Horace H. Rackham School of Graduate Studies Dissertation Grant, University of Michigan Museum of Zoology Grant, E. S. George Reserve Grant, and E. S. George Reserve Fellowship. Computer funds were provided by the University of Michigan Museum of Zoology. Preparation of this paper was supported by NSF grant DEB 78-07447.

I thank my daughter, Michelle, for her tireless assistance in the field and my wife, Sharron, who provided constant encouragement, typed all my manuscripts, and increased my fitness during the course of this study.

\section{Literature Cited}

Alcock, J., C. E. Jones, and S. L. Buchmann. 1977. Male mating strategies in the bee, Centris pallida Fox (Anthophoridae: Hymenoptera). Amer. Natur. 111:145-155.

AleXANDER, R. D. 1975. Natural selection and specialized chorusing behavior in acoustical insects, p. 35-77. In D. Pimentel (ed.), Insects, Science and Society. Academic Press. N.Y.

Alexander, R. D., AND G. Borgia. 1978. On the origin and basis of the male-female phenomenon. In M. F. Blum (ed.), Sexual Selection in Insects. Academic Press. N.Y.

Alexander, R. D., J. L. Hoogland, R. D. HowARd, K. M. NoOnan, and P. W. Sherman. 1978. Sexual dimorphisms and breeding systems in pinnipeds, ungulates, primates, and humans. In N. A. Chagnon, and W. G. Irons (eds.), Evolutionary Biology and Human Social Behavior. Duxbury Press. North Scituate, Mass.

Bartholomew, G. A. 1959. Mother-young relations and the maturation of pup behavior in the Alaskan fur seal. Anim. Behav. 7:163-171.

BatemaN, A. J. 1948. Intrasexual selection in Drosophila. Heredity 2:349-368.

Borgia, G. 1978. Sexual selection and the evolution of mating systems. In M. F. Blum (ed.), Sexual Selection in Insects. Academic Press. N.Y.

BOUCHER, D. H. 1977. On wasting parental investment. Amer. Natur. 111:786-788.

Brattstrom, B. H. 1974. The evolution of reptilian social behavior. Amer. Zool. 14(1):35-49.
Brockelman, W. Y. 1969. An analysis of density effects and predation in Bufo americanus tadpoles. Ecology 50:632-644.

Brown, J. L. 1964. The evolution of diversity in avian territorial systems. The Wilson Bull. 76(2):160-169.

Cantrall, I. J. 1943. The ecology of the Orthoptera and Dermoptera of the George Reserve, Michigan. Misc. Publ. Mus. Zool. Univ. of Mich. No. 54. 182 p.

Chagnon, N. 1974. Studying the Yanamamo: Studies in Anthropological Method. Holt, Rinehart, and Winston. N.Y. 270 p.

CoDy, M. L. 1971. Ecological aspects of reproduction. In D. S. Farner and J. R. King (eds.), Avian Biology. Vol. 1. Academic Press. N.Y. $148 \mathrm{p}$.

Collins, J. P. 1975. A comparative study of the life history strategies in a community of frogs. $\mathrm{Ph} . \mathrm{D}$. dissertation, Univ. of Mich. 148 p.

ConanT, R, 1975. A Field Guide to Reptiles and Amphibians of Eastern and Central North America. 2nd Ed. Houghton Mifflin Co., Boston. 429 p.

Cooper, A. W. 1958. Plant life forms as indicators of microclimate. Ph.D. dissertation, Univ. of Mich. 387 p.

Cronin, E. W., JR., and P. W. Sherman. 1977. $A$ resource-based mating system: the orangerumped honeyguide. Living Bird 15:5-32.

Darling, F. F. 1937. A Herd of Red Deer. Doubleday, N.Y. 226 p.

DARwin, C. 1871. Descent of Man and Selection in Relation to Sex. John Murray, London.

Davis, D. E. 1958. The role of density in aggressive behavior of house mice. Brit. J. Anim. Behav. 6:207-210.

1959. Territorial rank in starlings. Anim. Behav. 7:214-221.

Dawkins, R., and T. R. Carlisle. 1976. Parental investment, mate desertion, and a fallacy. $\mathrm{Na}$ ture 262:131-132.

Dole, J., AND P. Durant. 1974. Movements and seasonal activity of Atelopus oxyrhynchus (Anura: Atelopodidae) in a Venezuelan cloud forest. Copeia 1:230-235.

Draper, N., AND H. SMith. 1966. Applied Regression Analysis. John Wiley and Sons, N.Y. $407 \mathrm{p}$.

DUnBar, R., AND P. Dunbar. 1975. Social dynamics of Gelada baboons. Contrib. to Primatology. Vol. 6. S. Karger, Basel, Switzerland. 155 p.

EMLEN, S. T. 1968a. Territoriality in the bullfrog, Rana calesbeiana. Copeia 2:240-243.

$1968 b$. A technique for marking anuran amphibians for behavioral studies. Herpetologica 24(2):172-173.

1976. Lek organization and mating strategies in the bullfrog. Behavioral Ecology and Sociobiology 1:283-313.

EMLeN, S. T., AND L. W. ORING. 1977. Ecology, sexual selection, and the evolution of mating systems. Science 197:215-223.

Fabricius, E., AND K. J. Gustafson. 1954. Further aquarium observations on the spawning be- 
havior of the char, Salmo alpinus L. Inst. Freshwater Research Rep. No. 35:58-104.

Fisher, R. A. 1958. The Genetical Theory of Natural Selection. 2nd Edit. Dover Publ., N.Y. 291 p.

GENTRY, R. L. 1970. Social behavior of the stellar sea lion. Ph.D. dissertation, Univ. of Calif, , Santa Cruz. 113 p.

GeoRGE, I. D. 1940. Marking frogs for future reference in natural history studies. Copeia 1940:134.

GosNER, K. L. 1960. A simplified table for staging anuran embryos and larvae with notes on identification. Herpetologica 16:183-190.

Hamilton, W. D. 1966. The moulding of senescence by natural selection. J. Theo. Bio. 12:1245 .

Hogan-WARBURG, A. J. 1966. Social behavior of the ruff, Philomachus pugnax (L.). Ardea 54:109229.

Howard, R. D. 1974. The influence of sexual selection and interspecific competition on mockingbird song (Mimus polyglottos). Evolution 28:428438.

- 1977. The evolution of mating strategies and resource utilization in bullfrogs, Rana catesbeiana. Ph.D. dissertation. Univ. of Mich. 145 p.

- 1978. Factors influencing early embryo mortality in bullfrogs. Ecology, In press.

- 1979. Estimating fitness in natural populations. Amer. Natur., In press.

JENNI, D. A. 1974. Evolution of polyandry in birds. Amer. Zool. 14(1):129-144.

Kolson, R. A. 1973. Behavior of the bullfrog (Rana catesbeiana) with special emphasis on vocalizations. Ph.D. dissertation, Ohio State Univ. $181 \mathrm{p}$

KRUMMER, H. 1968. Two variations in the social organization of baboons, p. 293-312. In P. C. Jay (ed.), Primates, Studies in Adaptation and Variability. Holt, Rinehart, and Winston. N.Y.

LEBoEUf, B. J. 1974. Male-male competition and reproductive success in elephant seals. Amer. Zool. 4(1):163-176.

LICHT, L. E. 1976. Sexual selection in toads (Bufo americanus). Can. J. Zool. 54:1277-1284.

NoBle, G. K. 1954. The Biology of Amphibia. Dover Publ. N.Y. 577 p.

OrIANS, G. H. 1969. On the evolution of mating systems in birds and mammals. Amer. Natur. 103:589-603.

Rogers, J. S. 1942. The crane flies (Tipulidae) of the George Reserve, Michigan. Misc. Publ. Mus. Zool. Univ. of Mich. No. 53. 128 p.

RugH, R. 1962. Experimental Embryology. 3rd Ed. Burgess, Minneapolis. $501 \mathrm{p}$.

SavaGe, R. M. 1961. The Ecology and Life History of the Common Frog (Rana temporaria). Hafner Publ. Co. N.Y. 221 p.

Selander, R. K. 1965. On mating systems and sexual selection. Amer. Natur. 99:129-141.

- 1972. Sexual selection and dimorphism in birds, p. 180-230. In B. Campbell (ed.), Sexual Selection and the Descent of Man (1871-1971). Aldine Press. Chicago.

ShermaN, P. W. 1976. Natural selection among some group-living organisms. $\mathrm{Ph} . \mathrm{D}$. dissertation, Univ. of Mich. $270 \mathrm{p}$.

SIEgal, S. 1956. Nonparametric Statistics for the Behavioral Sciences. McGraw-Hill. N.Y. 312 p.

SoKal, R. R., AND F. J. RoHLF. 1969. Biometry. W. H. Freeman and Co. $776 \mathrm{p}$.

Steel, R. G. D., and J. H. Torrie. 1960. Principles and Procedures of Statistics. McGraw-Hill. N.Y. 481 p.

Trivers, R. L. 1972. Parental investment and sexual selection, p. 136-179. In B. Campbell (ed.), Sexual Selection and the Descent of Man (18711971). Aldine Press. Chicago.

VAN RHijn, J. G. 1973. Behavioral dimorphism in male ruffs, Philomachus pugnax (L.). Behaviour 47:10-229.

Watson, A., ANd G. R. Miller, 1971. Territory size and aggression in a fluctuating red grouse population. J. Anim. Ecol. 40:367-383.

WeLls, K. D. 1976. Multiple egg clutches in the green frog (Rana clamitans). Herpetologica 32(1):85-87.

- $1977 a$. Territorality and male mating success in the green frog (Rana clamitans). Ecology 58:750-762.

. 1977b. The social behavior of anuran amphibians. Anim. Behav. 25:666-693.

WIEWANDT, T. A. 1969. Vocalization, aggressive behavior, and territoriality in the bullfrog, Rana catesbeiana. Copeia 1969:276-285.

WILEY, R. H. 1974. Evolution of social organization and life history patterns among grouse. Quart. Rev. Bio. 49:201-227.

Williams, G. C. 1957. Pleiotropy, natural selection and the evolution of senescence. Evolution 11:398-411.

- 1966. Adaptation and Natural Selection, A Critique of Some Current Evolutionary Thought. Princeton Univ. Press. Princeton, N.J. 307 p. 1975. Sex and Evolution. Princeton Monographs No. 8. 200 p.

WonnacotT, T. H., and R. J. WonnacotT. 1972. Introductory Statistics for Business and Economics. John Wiley and Sons. N.Y. 622 p.

Wright, A. H., AND A. A. WRIGHT. 1949. Handbook of Frogs and Toads of the United States and Canada. Comstock Publ. Co., Ithaca, N.Y. $640 \mathrm{p}$. 